\title{
EVALUATION OF ACCIDENTS WITH DOMINO EFFECT IN LPG STORAGE AREAS
}

\author{
J. R. B. Alencar ${ }^{\mathrm{a}}$, \\ R. A. P. Barbosa $a^{a, b}$ \\ and M. B. de Souza Jr. ${ }^{\mathrm{a}}$ \\ ${ }^{a}$ Universidade Federal do Rio de Janeiro \\ Centro de Tecnologia, Escola de Química \\ Ilha do Fundão, Bloco E, Sala 207 \\ CEP 21949-900 \\ Rio de Janeiro - RJ - Brasil \\ Phone: 0055 [0] 212562.7636 \\ Fax: $0055[0] 21.2562 .7616$ \\ ${ }^{b}$ IESA - Projetos, Equipamentos e Montagens \\ Unidade de Óleo e Gás \\ Rua Mayrink Veiga, $09-9^{\circ}$ andar \\ CEP 20090-050 \\ Rio de Janeiro - RJ - Brasil

\begin{abstract}
The term domino effect denotes a chain of accidents, or situations, in which a fire/explosion load generated by an accident in one unit in an industry causes secondary and higher order accidents in other units. Such chains of accidents have a greater propensity to cause damage than stand-alone accidents. Most of the past risk assessment studies deal with accident in a single industry, more so in one of the units of an industry. But, often, accident in one unit causes a secondary accident in a nearby unit, which in turn may trigger a tertiary accident, and so on. The probability of occurrence and adverse impacts of such 'domino' or 'cascading' effects are increasing due to increasing congestion in industrial complexes and increasing density of human population around such complexes. Accidents with domino effect are seldom studied. LPG storage areas could produce the worst possible consequences in the event of an unforeseen incident. This work illustrates the application of models to evaluate the impacts of events with fire and explosion in LPG tanks on other similar units in the park and the possibility of occurrence of a domino effect. The criteria for occurrence of accidents with domino effect adopted in this work were $37.5 \mathrm{~kW} / \mathrm{m}^{2}$ in case of fire radiation and an overpressure of $0.7 \mathrm{~atm}$ in explosion cases in a receptor body. The spacing between LPG tanks was evaluated. The results show that such spacing is minimal and does not represent, as it should, a parameter indicating a safe distance able to prevent the propagation of an accident with domino effect.
\end{abstract} \\ Keywords: domino effect, fire, explosion, storage, LPG
}

\section{NOMENCLATURE}

$\mathrm{A}$
$\mathrm{b}$
$\mathrm{c}$
$\mathrm{d}$
$\mathrm{H}_{\mathrm{c}}$
$\mathrm{H}_{\mathrm{rel}}$
$\mathrm{L}$

result of Eq. (6)

constant

constant

constant

$$
\text { combustion heat, } \mathrm{J} / \mathrm{kg}
$$

relative humidity

L

distance from the center of the fire ball to the receptor body, $\mathrm{m}$

$\mathrm{m}$ mass of the inflammable substance present in the steam cloud, $\mathrm{kg}$

$\mathrm{m}_{\mathrm{f}} \quad$ mass of the substance involved in the fire ball, $\mathrm{kg}$

$\mathrm{O}_{\mathrm{p}} \quad$ peak of pressure, $\mathrm{psi}$

$\mathrm{q}$ radiation received by the receptor body, $\mathrm{W} / \mathrm{m}^{2}$

$\mathrm{R}_{\mathrm{f}} \quad$ radiant fraction of the ignition heat

$\mathrm{x}$ distance between the surface of the fireball and the receptive body, $\mathrm{m}$

$\mathrm{X}$ distance between the center of the explosion and the receptor body, $\mathrm{ft}$

$\mathrm{m}_{\mathrm{TNT}}$ mass equivalent of TNT in $\mathrm{lb}$ equal in effect to the mass $m$ in $\mathrm{kg}$

\section{Greek symbols}

$\tau_{\mathrm{a}} \quad$ atmospheric transmissivity

$\eta \quad$ efficiency of the explosion

\section{INTRODUCTION}

In the analysis of 'conventional' risks, the process units of a petro-chemical plant are examined separately, taken into consideration only their intrinsic risks. When the process risks of two or more units are analyzed simultaneously, the resulting risk of the plant can be potentialized in such a way that a chemical accident that originated in one of the units of the plant can cause its impact to trigger new accidents in other units in a chain reaction known as the domino effect. This can lead to more disastrous consequences than the ones expected from isolated risks in each one of the process units. The same analysis can be applied to distinct industrial plants located in the same industrial park separated by regulated distances that certainly do not prevent the simultaneity of the risks of distinct process units. It concerns a more realistic view on the process risks (Khan and Abbasi, 2001). 


\section{TECNOLOGIA/TECHNOLOGY}

Very little research has been done on the effects of accidents with domino effect. The manner in which the subject has been approached in literature almost always restricts itself to descriptions and interpretations of the occurred events and phenomena in a qualitative way (Khan and Abbasi, 1999). In one of the few quantitative studies on domino effect accidents, Latha et al. (1992), the various manners in which accidents with fire can provoke domino effect accidents were studied. Besides fire, the most common forms of domino effect accidents are explosion events in which fragments of tank surfaces are launched or pressure waves occur. According to Kourniotis et al. (2000), the movement of inflammable substances when transported under pressure is the most common cause of accidents with domino effect.

Nowadays, legislation in various countries already demands evaluations on the possible occurrences of domino effect accidents in risk analysis studies. In Brazil, such a legislation has not been implemented yet, but with the ratification of the Number 174 Convention of the OIT-International Labour Organization (Brasil, 2002), it has become clear that it is very unlikely, considering this new world reality, that this topic will not be included in the regulations that are to come.

The storage areas of LPG tank park in petrochemical plants are areas that are quite susceptible to occurrences of chemical accidents with domino effect, triggered mainly by fire or explosion, due to the large inventory of inflammable products that normally accumulate as well as to the operational conditions itself - high pressure and temperatures above the normal boiling point.

The purpose of this article is to evaluate the dimension of the impact caused by chemical accidents triggered by fire and/or explosion in LPG tank parks and to evaluate its potential to cause secondary accidents, that is, a domino effect. The spacing between tanks located in the same park or between these and process units, as foreseen in codes and national and international norms, will be evaluated.

\section{METHODOLOGY}

The scenarios studied in this article will be based on the occurrence of fire and/or explosion as primary events in a LPG tank park.

\section{Fire as Initiatory Event}

In case of fire, radiation is the main effect. The higher the quantity of substances involved in the accident, and also the closer to the source of the accident, the higher the radiation will be. According to AlChE, cited by Khan and Abbasi (1998), a heat flow of $37.5 \mathrm{~kW} / \mathrm{m}^{2}$ is sufficient to cause severe damage to process equipment in other installations that operate under atmospheric conditions and, consequently, sufficient to provoke new accidents. In case of an operation involving temperature and pressure, a heat flow of this intensity makes the adjacent areas even more vulnerable.

The radiation of a ball of fire incident on a receptor body at a distance $L$ from the center of the same can be expressed by Eq. (1) (Louvar and Louvar, 1998).

$$
q \frac{2.2 \cdot V_{a}}{4 \mathcal{S}^{2}} \cdot R_{f} \cdot H_{c} \cdot m_{f}^{0.67}
$$

where $q$ is the radiation received by the receptor body in $\mathrm{W} / \mathrm{m}^{2}, H_{c}$ is the combustion heat in $\mathrm{J} / \mathrm{kg}$; $m_{f}$ is the mass in $\mathrm{kg}$ of the substance involved in the fire ball; $\tau_{a}$ is the atmospheric transmissivity; $R_{f}$ is the radiant fraction of the ignition heat and $L$ is the distance from the center of the fire ball to the receptor body. This study intends to evaluate the quantity in relation to the stored quantity $m_{f}$ determining the value of $q$ equal to $37.5 \mathrm{~kW} / \mathrm{m}^{2}$. Reorganizing the Eq. (1), we obtain Eq. (2):

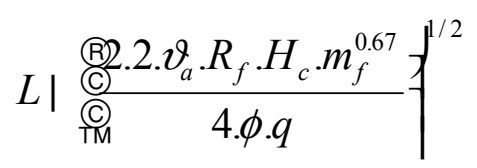

with $\tau_{a}$ given by Louvar and Louvar (1998):

$$
\text { W } \log \left(14.1 . H_{r e l}^{\square 0.108} \cdot x^{\square 0.13}\right)
$$

where $H_{r e l}$ is the relative humidity and $x$ the distance between the surface of the fireball and the receptive body in meters using the spacing between the unit tanks. The following parameters were used in the simulations: $50 \%$ for $H_{\text {rel }}, 0.3$ for $R_{f}$ and $H_{c}$ equal to $46333 \mathrm{~J} / \mathrm{kg}$ for LPG. 


\section{Explosion as Initiatory Event}

In case of explosion the damaging effects are the result of overpressure originated by shockwaves of the steam cloud involved in the accident. According to Khan and Abbasi (1998), a peak of pressure resulting from a $0.7 \mathrm{~atm}$ explosion is enough to cause severe damage to process equipment and thus provoke new accidents, either associated to new explosions or new events involving fire.

The peak of pressure in an explosion of a steam cloud incident on a receptor body at a distance $L$ from the center of the latter can be expressed by Eq. (4):

$$
X \quad m_{T N T}^{1 / 3} \cdot A
$$

where $X$ is the distance in $\mathrm{ft}$ between the center of the explosion and the receptor body and $m_{T N T}$ is the mass equivalent of TNT in $1 \mathrm{~b}$ able to cause the same effect as the mass $m$ in $\mathrm{kg}$ of the inflammable substance contained in the steam cloud:

$$
m_{T N T} \frac{2.205 . m \cdot H_{c} \cdot K}{4686}
$$

where $m$ is the mass of the inflammable substance in $\mathrm{kg}$ present in the steam cloud and $\eta$ is the efficiency of the explosion.

The parameter $A$ is the result of Eq. (6), where $O_{p}$ represents the peak of pressure in psi, which is to be evaluated based on the location of the explosion. (USA, 1998)

$$
A \quad \exp \left(b \square c \cdot \ln \left(O_{p}\right) \square d \cdot \ln \left(O_{p}\right)^{2}\right)
$$

where: $b, c$, and $d$ are constant and equal to 3.5031, -0.7241 and 0.0398 , respectively.

The purpose of this study is to evaluate the quantity $X$ in relation to the stored quantity $m$, converted into the TNT mass equivalent by Eq. (5) and fixing the $O_{p}$ value equal to $10.23 \mathrm{psi}(0.7 \mathrm{~atm})$ and $\eta$ equal to 0.03 and $H_{c}$ equal to $46.333 \mathrm{~kJ} / \mathrm{kg}$.

\section{Spacing Between Tanks}

The spacing between LPG storage tanks is usually fixed based on the accumulated experience in similar plants, which has certainly given rise to a series of existent norms or standards. Often such references are observed without due analyses of the risks of each plant and without verifying to what extend these distances provide security. Taking into account the reality of the domino effect accidents, new minimum spacing values between tanks must be adopted, since the risks tend to become potentialized. Also a project criterion, as to the nonoccurrence of such accidents, can be utilized to determine the location of the tanks.

There are few existent standards in Brazil that deal with spacing between tanks and other units. The regulating norm NR-20 (Brasil, 1978) is one of them, however it concerns a quite antiquated legal implement, limited and hardly enlightening. Another more recent norm (Brasil, 1999) suggests that the minimum distance between one LPG vessel and another vessel storing either LPG or other inflammable product under pressure, should be in accordance with the following minimum measures:

a) for spherical vessels:

$1 / 2$ the diameter (in case of different diameters, regard the biggest);

b) for cylindrical vessels in one battery:

$3 / 4$ diameter (in case of different diameters, regard the biggest), however not less than 1.5 meters;

c) from spheres to cylinders or battery of cylinders:

$1 / 2$ diameter of the sphere, however not less than 7.5 meters;

d) between batteries of cylinders:

7.5 meters.

The parameters $L$ and $X$ were compared to regulated minimum distances as to determine whether the latter follows the requirements of nonoccurrence of domino effect accidents.

\section{RESULTS AND DISCUSSION}

Initially, a basic measurement of the LPG storage tanks was made taking into account the spherical and cylindrical shapes of the tanks as well as the LPG storage capacity at $25^{\circ} \mathrm{C}$. The volume equivalent to the LPG mass stored with a $10 \%$ factor added was used as a criterion for the measurement of the spherical tanks. For the cylindrical tanks the same volumes as for the spherical tanks were used with optimal L/D ratios suggested by the Process Associates of America (2004). 


\section{TECNOLOGIA/TECHNOLOGY}

Table 1 shows the values, obtained by the measurement of the tanks with the same capacity, that constitute the hypothetical tank park here studied, as well as the respective spacing between tanks, taking into consideration the criterion of the PETROBRAS norm (Brasil, 1999), aforementioned. In this table the values $\mathrm{D} / 2$ and $3 / 4 \mathrm{D}$ represent, respectively, the spacing between spherical and cylindrical tanks obtained based on their diameters and the utilized norm. $\mathrm{L}_{\mathrm{TT}}$ represents the distance between the tangent lines of the horizontal cylindrical tanks.

Table 1. Tank dimensions and spacing between tanks (m) versus LPG Storage Capacity (ton)

\begin{tabular}{cccccc}
\hline & \multicolumn{3}{c}{ Spherical Tanks } & \multicolumn{3}{c}{ Cylindrical Tanks } \\
$\mathrm{m}$ & $\mathrm{D}$ & $\mathrm{D} / 2$ & $\mathrm{~L}_{\mathrm{TT}}$ & $\mathrm{D}$ & $3 / 4 \mathrm{D}$ \\
\hline ton) & & & & \\
\hline 0.5 & 1.37 & 0.69 & 2.11 & 0.78 & 1.5 \\
1 & 1.73 & 0.87 & 2.91 & 0.94 & 1.5 \\
2 & 2.18 & 1.09 & 3.98 & 1.13 & 1.5 \\
5 & 2.96 & 1.48 & 6.24 & 1.50 & 1.5 \\
10 & 3.73 & 1.87 & 8.44 & 1.82 & 1.5 \\
20 & 4.70 & 2.35 & 11.38 & 2.22 & 1.7 \\
30 & 5.38 & 2.69 & 13.62 & 2.50 & 1.9 \\
40 & 5.92 & 2.96 & 15.38 & 2.72 & 2.0 \\
50 & 6.38 & 3.19 & 16.96 & 2.90 & 2.2 \\
75 & 7.30 & 3.65 & 20.14 & 3.26 & 2.4 \\
100 & 8.04 & 4.02 & 22.75 & 3.54 & 2.7 \\
200 & 10.12 & 5.06 & 30.48 & 4.33 & 3.2 \\
500 & 13.74 & 6.87 & 44.82 & 5.65 & 4.2 \\
1000 & 17.31 & 8.66 & 59.90 & 6.91 & 5.2 \\
\hline
\end{tabular}

Next, scenarios involving fire and explosion were created using a 'worst case' methodology, which involves all of the LPG content present in the two tanks in the accident. The fire and explosion events were examined separately and their respective impacts, capable of provoking successive accidents of equal potential in other similar tanks in the same park, were determined. Table 2 presents the results of this range based on the storage capacity in the tank where the event originated. It is important to bear in mind that for cylindrical tank diameters, D/1.82, a minimum spacing foreseen by the norm was adopted.

When analyzing the results in Tabs. 1 and 2 , it can be noted that the values for $L$ as well as the values for $\mathrm{X}$ are much higher than the distances $\mathrm{D} / 2$ and 3/4D for spherical or cylindrical tanks respectively. We can conclude from this affirmative that such spacing is not able to prevent the propagation of similar events to other tanks in a domino effect. Figure 1 presents a visualization of the comparison of these values. From this figure it can also be concluded that the range of accidents triggered by fire is further than the ones triggered by explosion for any of the geometric shapes of the tanks studied.

The maximum value of the relation between the range and the spacing between the tanks can be taken from Tab. 1 and 2, seeking to determine a coefficient for such spacing in order to make them acceptable when an analysis of domino effect is contemplated.

Table 2. Impact caused by Fire (L) and Explosion (X) in LPG tanks

\begin{tabular}{ccc}
\hline $\mathrm{m}$ (ton) & $\mathrm{L}(\mathrm{m})$ & $\mathrm{X}(\mathrm{m})$ \\
\hline 0.5 & 1.87 & 1.60 \\
1 & 2.36 & 2.02 \\
2 & 2.97 & 2.54 \\
5 & 4.04 & 3.45 \\
10 & 5.38 & 4.35 \\
20 & 6.73 & 5.48 \\
30 & 7.68 & 6.27 \\
40 & 8.43 & 6.90 \\
50 & 9.07 & 7.43 \\
75 & 10.34 & 8.51 \\
100 & 11.35 & 9.36 \\
200 & 14.22 & 11.80 \\
500 & 19.13 & 16.01 \\
1000 & 23.95 & 20.17 \\
\hline
\end{tabular}

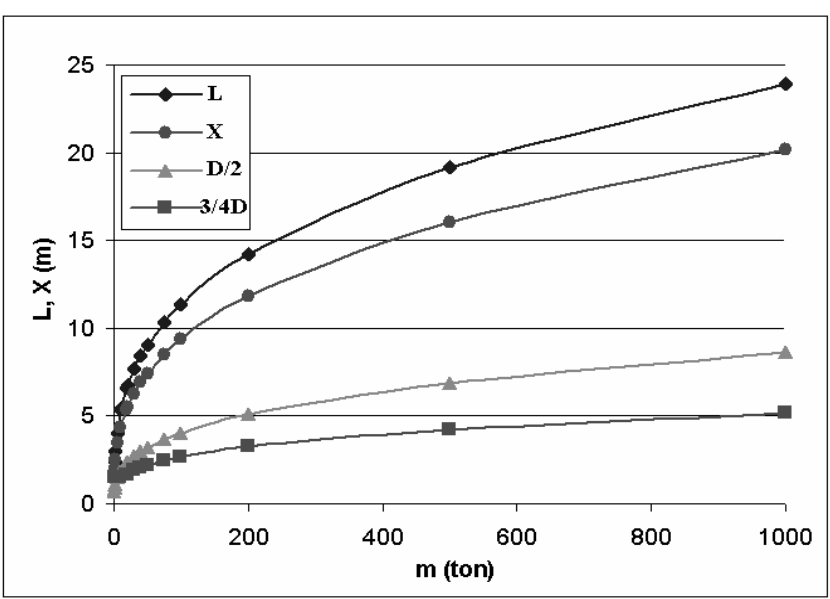

Figure 1. Relation between the range of the accidents and the spacing between the tanks

Table 3 presents a summary of the obtained relations. When analyzing such numbers, it can be observed that the distances foreseen by the norm, should be increased about 3 and 5 times for 
spherical and cylindrical tanks, respectively, so that the criteria here studied, the occurrence of domino effects, will not be attained.

Table 3. Relation between the obtained range and the spacing as foreseen by the norm.

\begin{tabular}{ccc}
\hline Event & Spherical Tank & Cylindrical Tank \\
\hline Fire & 2.88 & 4.62 \\
Explosion & 2.33 & 3.89 \\
\hline
\end{tabular}

\section{CONCLUSIONS}

The evaluation of the impact of a domino effect accident should be an integrated constituent of any study of risk analysis. It concerns a recent reality noticed due to the tragic history of many past accidents and a more realistic way of dealing with intrinsic risks of chemical and petrochemical plants. The domino effect accidents are almost always triggered by fire and/or explosion in some process units, their damage being propagated to other units and able to provoke secondary accidents in other equipments or process units. In this research, it was shown that LPG tank parks are vulnerable with regard to the occurrence of domino effect accidents. The spacing between tanks was evaluated in relation to the adherence to this parameter as a protection measure against accidents of this nature. The impact caused by fire and explosion in LPG tanks is strong enough to destroy other tanks and to overcome 'safe' distances adopted in many plants, usually based on antiquated technical norms that have not incorporated the domino effect reality yet. The simple implementation of spacing between tanks or process units suggested by technical norms has become a practice of antiquated engineering. Analysis of the process risks, as well as evaluation of the consequences of the most probable accidents and the incorporation of a study on the possibility of domino effects have become vital in order to minimize these effects. The results obtained in this study can be quite enlightening in relation to the spacing that can be adopted as yet another plant security measure.

\section{REFERENCES}

Brasil, 2002, Decreto $\mathrm{N}^{\circ} 4085$ de 15.01.2002, Diário Oficial da União 16.01.2002 (in Portuguese).

Brasil, 1999, PETROBRÁS N-1645, Critérios de Segurança para Projeto de Instalações Fixas de Armazenamento de Gás Liqüefeito de Petróleo, (in Portuguese).

Brasil, 1978, Ministério do Trabalho, Portaria MTb No3214 de 08.06.1978 (in Portuguese).

Khan, F. I. and Abbasi, S. A., 2001, Estimation of probabilities and likely consequences of chain of accidents (domino effect) in Manali Industrial Complex, Journal of Cleaner Production, 9, pp. 493-508.

Khan, F. I. and Abbasi, S. A., 1999, Major accidents in process industries and an analysis of causes and consequences, Journal of Loss in the Process Industries, 12, pp. 361-378.

Khan, F. I. and Abbasi, S. A., 1998, Models for Domino Effect Analysis in Chemical Process Industries, Process Safety Progress, 17, No. 2, pp. 107-123.

Kourniotis, S. P. Kiranoudis, C. T., Markatos, N. C., 2000, Statistical Analysis of Domino Chemical Accidents, Journal of Hazardous Materials, 71, pp. 239-252.

Latha, P., Gautam, G., Raghavan, K. V., 1992, Strategies for Quantification of Thermaly Initiated Cascade Effects, Journal of Loss in the Process Industries, 5, No. 1, pp. 18-27.

Louvar, J. F., and Louvar, B. D., 1998, Health and Environmental Risk Analysis Fundamentals With Applications, Prentice Hall PTR.

Process Associates of America, 2004, Optimum Dimensions of a Vessel, found at http:// www.processassociates.com, Accessed on 05.01.2004.

USA, 1989, EPA, FEMA, DOT, Handbook of Chemical Hazard Analysis Procedures. 